\title{
Genetic diversity of Varroa destructor parasitizing Apis mellifera unicolor in Madagascar
}

\author{
Henriette RASOLOFOARIVAO ${ }^{1,2}$, Johanna CLÉMENCET ${ }^{3}$, Adrien SPECK ${ }^{1}$, \\ Lala Harivelo Raveloson-Ravaomanarivo ${ }^{2}$, Bernard Reynaud ${ }^{1}$, Hélène Delatte ${ }^{1}$ \\ ${ }^{1}$ CIRAD, UMR PVBMT, 7, chemin de l'IRAT, 97410, Saint Pierre, La Réunion, France \\ ${ }^{2}$ Département d'Entomologie, Faculté de Sciences, Université d'Antananarivo, B.P. 906, 101, Antananarivo, Madagascar \\ ${ }^{3}$ Université de La Réunion, UMR PVBMT, 97715, Saint Denis cedex 9, La Réunion, France
}

Received 4 August 2016 - Revised 1 February 2017 - Accepted 31 March 2017

\begin{abstract}
Varroa destructor is an invasive alien species that has been reported parasitizing the endemic honey bee of Madagascar, Apis mellifera unicolor, since 2010. Studying its nuclear genetic diversity and structure was our main goal. Using 11 microsatellite loci and 344 mites collected from 12 apiaries, we observed a low genetic diversity, with only 8 multilocus genotypes (MLG) identified. $V$. destructor populations form a single genetic cluster, clonal richness ranged from 0.02 to 0.20 , and number of MLG within apiaries varied between one and six MLGs. About $69.5 \%$ of the mites analyzed harbored the same genotype (100\%, homozygous), and $23.3 \%$ had a genotype differing by a single allele. The overall low diversity observed suggests one or multiple introductions of similar genotypes. The greater abundance of MLGs in High Land apiaries (eight MLGs) than on the east coast (two MLGs) and the presence of particular MLGs in High Land apiaries favor the hypothesis that V. destructor has been first introduced close to the international airport, and then spread to other regions by commercial exchanges.
\end{abstract}

\section{microsatellite / multilocus genotypes / Varroa destructor / Madagascar}

\section{INTRODUCTION}

Invasive species are known as a leading threat to biodiversity as well as an increasing economic concern (Wilcove et al. 1998; Pimentel et al. 2000). Especially when invasive species are parasitizing endemic generalist pollinators in hotspot of biodiversity implying their decline, it could have dramatic ecologic and economic impact (Potts et al. 2010).

Electronic supplementary material The online version of this article (doi:10.1007/s13592-017-0509-3) contains supplementary material, which is available to authorized users.

Corresponding author: H. Delatte, helene.delatte@cirad.fr

Manuscript editor: Peter Rosenkranz
Studies about genetic diversity of invasive populations can provide an indication of the amount of genetic variation lost during the colonization bottleneck and can provide evidence of multiple sources of introduction (Sakai et al. 2001). At the founding stage, the number of individuals introduced is usually small and contains only a low portion of the "genetic pool" present in the area of origin (Lee 2002). Furthermore, the level of genetic diversity in the invaded zone depends on the contribution of individuals from different populations of the source area. Indeed, when the introduced individuals originated from genetically heterogeneous populations, genetic mixing between populations in the new environment colonized could generate a higher genetic diversity (Dlugosch and Parker 2008). The reproduction system of the introduced species plays also an important role in modulating the genetic diversity (Lynch 1984). 
Although Varroa destructor (Mesostigmata: Varroidea) is an obligate ectoparasite mite and shows a sexual reproduction mode, mating takes place between brother and sisters, increasing inbreeding. This reproduction system (adelphogamy), coupled with the haploid-diploid (De Ruijter and Pappas 1983; Martin et al. 1997) and pseudo-arrhenotoky sex determination systems (Martin et al. 1997), are responsible for the observed high deficit of heterozygotes and greatly increases the fixation rate of mutations (Cornuet et al.2006). In case of multi-infested honeybee brood cells by $V$. destructor, particularly when heavy infestation of the colony is observed, male could mate with non-sisters (female offspring from other female founder) and it could limit the inbreeding, permitting genetic mixing within populations (Solignac et al. 2005).

Spread of honeybee subspecies has facilitated the transfer of $V$. destructor from one host to the other. V. destructor shifted from its original Asiatic host Apis cerana (Hymenoptera: Apoidea) and invaded the subspecies Apis mellifera (Denmark et al. 1991; Fazier et al. 2010). The first observation of $V$. destructor on A. mellifera was reported in 1957 in Asia, then, this invasive alien species (Handley et al. 2011; Barlow et al. 2002) became one of the most common pests of A. mellifera .

$V$. destructor was first reported in Madagascar in 2010 (OIE- Feb-2010; Rasolofoarivao et al. 2013) and has been observed parasitizing Apis mellifera unicolor (Latreille 1804) the endemic honey bee (Ruttner 1988), of the African lineage (Franck et al. 2001; Rasolofarivao et al. 2015b). The impact of the parasite on A. m. unicolor was severe (Rasolofoarivao et al. 2013, 2015a), despite its African genetic background. Indeed, it was reported that populations of A lineages, and notably Apis mellifera scutellata, were able to better tolerate $V$. destructor infestation (Strauss et al. 2015, 2016; Mortensen et al. 2016). Nevertheless, the spread of the mite is still relatively limited to the High Lands and the east coast regions (Rasolofarivao et al. 2015b). In this work, we examined the nuclear genetic diversity of $V$. destructor in Madagascar with microsatellite markers.

\section{MATERIALS AND METHODS}

\subsection{V. destructor sampling}

Sampling of phoretic $V$. destructor was carried out from January 2011 to January 2012 in 69 managed colonies from 12 infested apiaries (Figure 1, Table I) of the endemic honeybee subspecies A. M. unicolor (Rasolofoarivao et al. 2015b). Two apiaries were located on the east coast and 10 in the High Lands region. Worker honeybees were randomly sampled inside the hive and preserved in $96 \%$ ethanol. Number of workers sampled per apiary varied between 2 and 315 . In the laboratory, tubes were vigorously shaken to dislodge $V$. destructor from the bodies of the worker, and each worker was visually inspected to remove any mites on the bee's surfaces. Samples were stored separately in a new tube with $96 \%$ ethanol and frozen at $-20{ }^{\circ} \mathrm{C}$ until they were processed.

\subsection{DNA extraction and genotyping of $\boldsymbol{V}$. destructor}

Total DNA of $480 \mathrm{~V}$. destructor was isolated using the protocol of extraction as previously described (Delatte et al. 2010); it consists in extracting DNA from whole mite by crushing them individually in a sodium dodecyl sulfate (SDS)/Proteinase $\mathrm{K}$ buffer and precipitating DNA in ethanol, then elute it in pure water.

DNA of each sample was amplified at $12 \mathrm{mi}-$ crosatellite loci: two (vj292, vj295) among those published by (Evans (2000) and 10 (VD001, VD016, VD112, VD114, VD119, VD126, VD146, VD152, VD154, VD163) by Solignac et al. (2003). PCR reactions were performed in a $10-\mu \mathrm{L}$ final reaction volume using two primer mix and Type-it Multiplex PCR Master Mix (QIAGEN) kits. PCR program was run with an initial denaturation at $95{ }^{\circ} \mathrm{C}$ for $5 \mathrm{~min}$, followed by 40 cycles at $95^{\circ} \mathrm{C}$ for $30 \mathrm{~s}$, annealing for $1 \mathrm{~min}$ at $55^{\circ} \mathrm{C}$, and then elongation at $72{ }^{\circ} \mathrm{C}$ for $1 \mathrm{~min}$. A final extension step was done at $72{ }^{\circ} \mathrm{C}$ for $10 \mathrm{~min}$. PCR products were then prepared for capillary electrophoresis and genotyped using an automated DNA sequencer by Applied Biosystems (AB). Electrophoresis profiles were obtained by $A B$ 

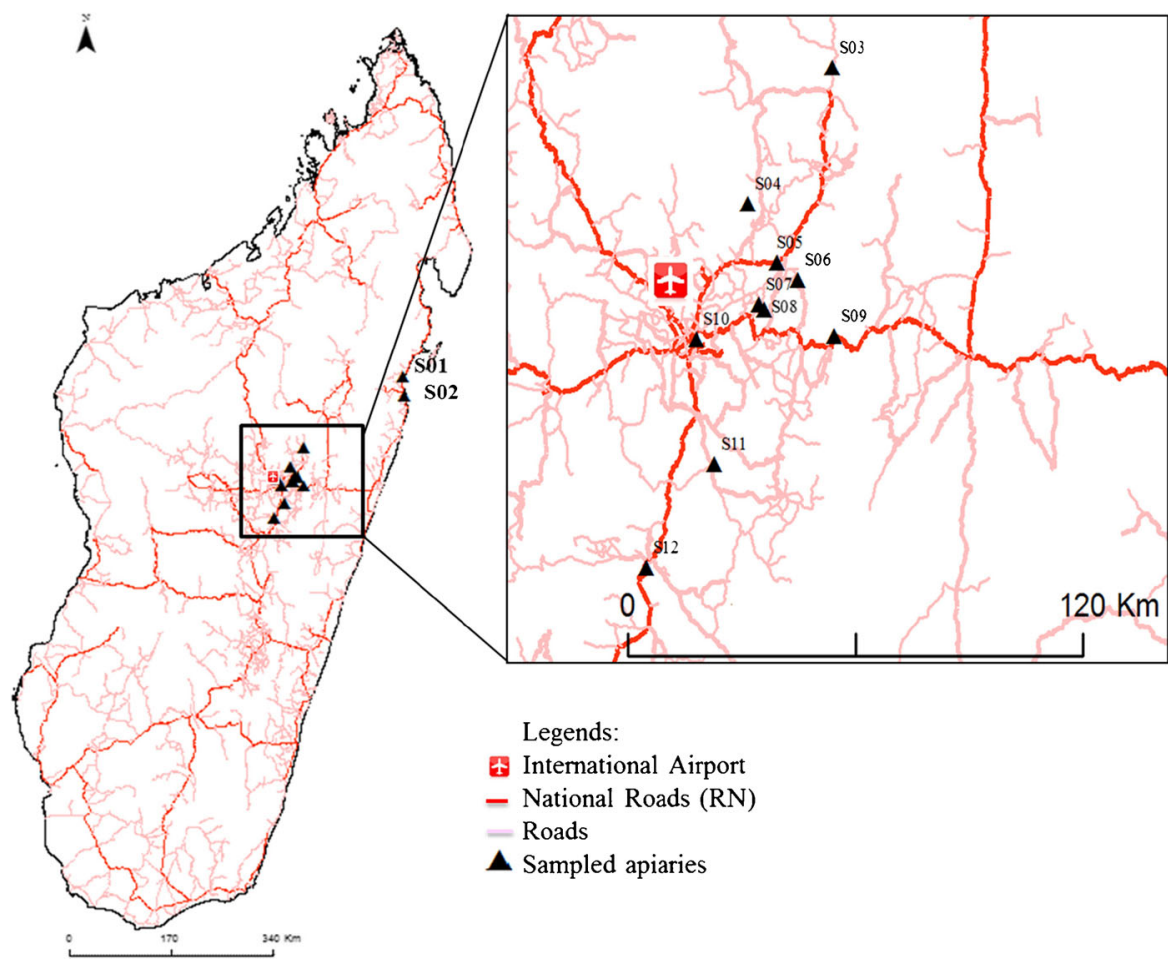

S03 $(1,2,3)$

S04 $(1,2,3)$

S05 $(1,2,3,4,5,8)$

S06 $(1,2)$

S07 $(1,2)$

S08 $(1,2,3,6,7)$

S09 $(1,2,3,4)$

S10 $(1,2)$

$\mathrm{S} 11(2)$

S12 $(1,2)$

Figure 1. Location of the 12 apiaries sampled to study genetic diversity and structure of $V$. destructor. For each apiary (names indicated in Table I), the different multilocus genotypes (MLGs) observed are given (at right).

3130XL data collection. Allele identification at the size standard using the Genemapper V. 4.0 each locus was performed by comparison with software (AB).

Table I. Apiary information for each sampled apiary is given: number of colonies and mites collected (number in parenthesis refers to individuals that have not been used for molecular analysis), sampling years and the multilocus genotypes (MLG)

\begin{tabular}{llllll}
\hline Apiaries codes & Apiaries' location & Number of colonies & Number of mites & Sampling year & MLG detected \\
\hline S01 & Rantolava & 1 & 1 & 2012 & 1 \\
S02 & Mahambo & 2 & 5 & 2012 & 1,2 \\
S03 & Masakalina & 4 & 7 & 2012 & $1,2,3$ \\
S04 & Ambohitrolomahitsy & 6 & 15 & 2012 & $1,2,3$ \\
S05 & Amby & $(3) 11$ & $(103) 136$ & 2011 & $1,2,3,4,5,8$ \\
S06 & Ambotseheno & 6 & 8 & 2012 & 1,2 \\
S07 & Anjepy & 7 & 13 & 2012 & 1,2 \\
S08 & Betoho & $(4) 11$ & $(110) 231$ & 2011 & $1,2,3,6,7$ \\
S09 & Mandraka & 1 & 20 & 2012 & $1,2,3,4$ \\
S10 & Ankatso & $(9) 2$ & $(12) 9$ & 2011 & 1,2 \\
S11 & Andramasina & 1 & 6 & 2012 & 2 \\
S12 & Ambatolampy & 1 & 29 & 2012 & 1,2 \\
\hline
\end{tabular}




\subsection{Population genetic analysis}

Individuals with missing genotype data were excluded from analysis. Only apiaries with at least 10 samples were considered for the population genetics analysis. All pairs of loci were tested for linkage disequilibrium using the probability test in Genepop V. 4.2 (Rousset 2008). Gene diversity within populations was estimated using observed $\left(\mathrm{H}_{\mathrm{O}}\right)$ and expected $\left(H_{\mathrm{E}}\right)$ heterozygosity implemented in Genepop V.4.2 (Rousset 2008). Single and multilocus Fixation Index $\left(F_{\text {IS }}\right)$ were estimated through the fixation index (Weir and Cockerham 1984). Deviations from HardyWeinberg Equilibrium (HWE) were tested using a two-tailed Fisher's exact test based on Markovchain randomization (1000 dememorizations with 100 batches and 1000 iterations per batch (Rousset 2008). As the number of alleles observed within a given population could be positively affected by the sample size (Leberg 2002), allelic richness, adjusted by the lowest sample size (Leberg 2002), was calculated using Fstat V. 2.9 (Goudet 2001). Weir's pairwise $F_{\mathrm{ST}}$ (Weir and Cockerham 1984) were calculated across all population pairs in order to assess genetic differentiation between apiaries.

Levels of population admixture were quantified through a number of Bayesian clustering procedures implemented in Structure 2.3.4 (Pritchard et al. 2000). Structure calculates clustering patterns solely based on MLG (Falush et al. 2007). The number of clusters was inferred according to Evanno et al. (2005), and the ad hoc statistic was calculated for $K$ ranging from 1 to 20. Structure was run for 1 million generations (burn-in $=100,000$ generations) with 10 iterations for each value of $K$. Ad-Hoc statistic was processed though the Structure harvester website (http://taylor0.ucla.edu/structureHarvester/).

\subsection{MLG diversity}

Multilocus genotypes (MLGs) were assigned using the GenClone V. 2.0 software (ArnaudHaond and Belkhir 2007). Spearman's rank test was used to test correlation between sample sizes and number MLG found per site. Level of clonality was estimated using genotypic richness
$(R)$, with $R=0$ when population consists in a single MLG, and 1 when each individual possesses a unique MLG. The Simpson index $(D$, also known as Nei's genetic diversity), with values corrected for finite sample sizes, was calculated (D ranging from zero to one, with higher values corresponding to greater clonality diversity). Finally, the Evenness $(E)$ which is the measure of how MLG are distributed and their abundance among sample was also calculated ( $E$ ranging from 0 to 1 , with 1 indicating that all MLGs have equal abundance). All indices were calculated per apiary using the GenClone V. 2.0 software (Arnaud-Haond and Belkhir 2007).

Matrix of pairwise distances between distinct MLG was used to construct a minimum spanning network using the NETWORK 4.6.1.2 software (Polzin and Daneshmand 2003).

\section{RESULTS}

\subsection{Genetic diversity}

Of the 480 mites analyzed, 344 were successfully genotyped at 11 of the microsatellite loci. Among the set of 11 primers considered, only 3 were polymorphic (VD001, VD112, vj295). Number of alleles at the three polymorphic loci was two alleles for VD112, three for VD001, and four for vj295 (Table II). A total of 11 alleles across the 11 loci were congruent with previous studies on $V$. destructor worldwide populations (Table II) by Evans (2000) and Solignac et al. (2003). New alleles such as 125 and 127 were found in locus VD001, allele 110 in VD112, and allele 140 and 143 in vj295. No significant linkage disequilibrium between pair of loci was detected (Fisher's exact test, $P>0.05$ ).

\subsection{Clonal diversity}

A total of eight MLGs were found and coded from 1 to 8 (Table II). MLGs were not equally represented (Figure 2). MLGs 1 and 2 account for $92.8 \%$ of the data set, 69.5 and $23.3 \%$, respectively (Table II). The most frequent MLG (1) was homozygous at all loci.

Six MLGs (2, 3, 5, 6, 7, and 8) were heterozygous at one locus only, deriving from one 


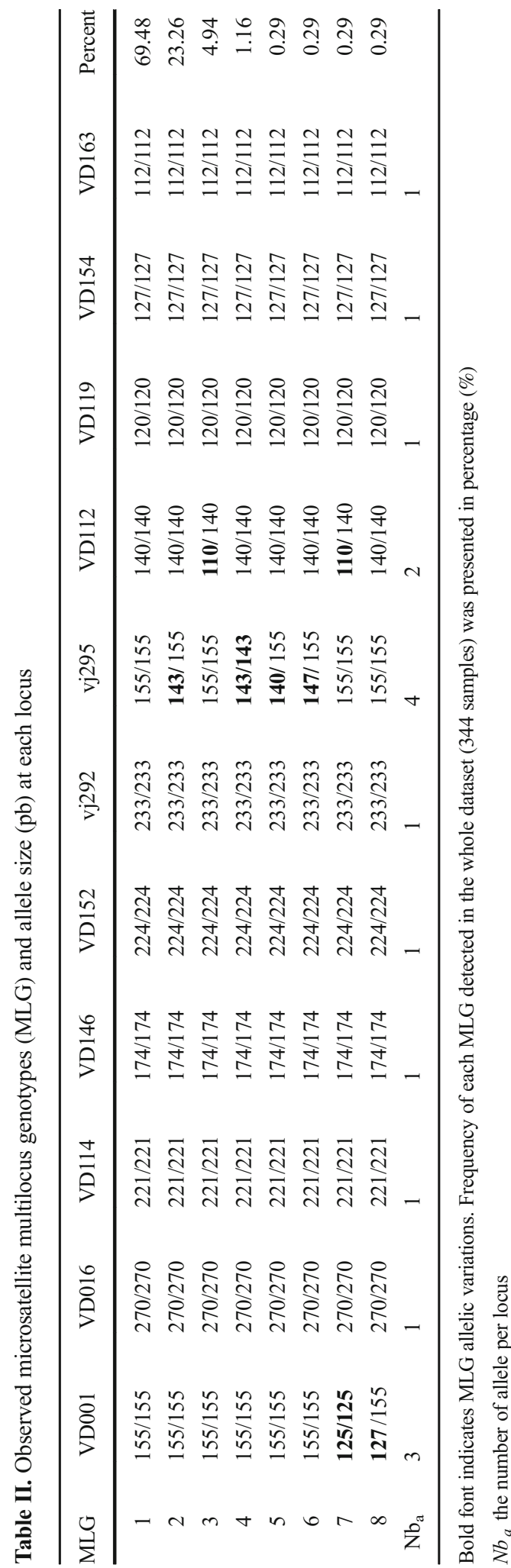

mutation event from the dominant one (except MLG 7, with three alleles distinct from MLG 1, Figure 2). MLG 4 was also homozygous at all loci, showing two allele differences with MLG 1 (Figure 2). Distribution of the pairwise number of allele differences between MLGs in the whole data set appeared uni-modal with one to five alleles of difference between MLGs (Figure 2).

The number of MLGs per apiaries ranged from one (S01 and S11) to six (S05). The two most frequent MLGs (1 and 2) were found in all apiaries (except in S01 for MLG 1 and S11 for MLG 2). All MLGs were identified in the High Lands region. In contrast, on the east coast, with only six mites analyzed, only two MLGs were detected (MLG 1 and MLG 2). Four MLGs were detected only once, MLG 5 and MLG 8 in S05 and MLG 6 and MLG 7 in S08, both apiaries being located next to the international airport and were also the most extensively sampled sites (Table III).

\subsection{Structure of the genetic diversity within and among apiaries}

Mean allelic richness within apiaries was very low and close to 1 (1.09-1.18, see Table III). Levels of expected heterozygosity were close to

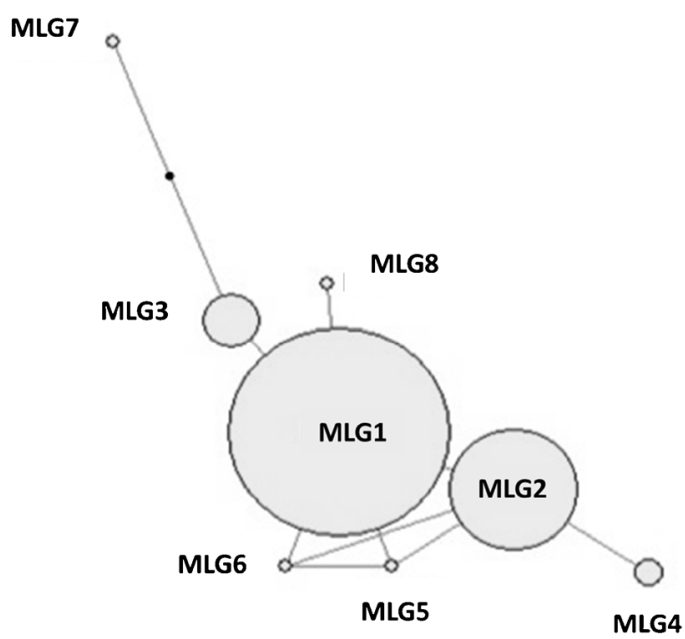

Figure 2. Minimum spanning network of $V$. destructor genetic distances computed as number of allele differences between MLGs (11 microsatellite loci). Each circle represents a different MLG, circle size is proportional to sample size, and line between the circles indicates a difference of one allele. 
Table III. Descriptive statistics of genetic and clonal diversity across all loci (11 microsatellite loci) for 6 of the 12 populations (i.e., only apiaries with more than 10 individuals successfully genotyped were presented)

\begin{tabular}{lccccccccl}
\hline Apiary & Number & $G$ & $R$ & $D$ & $E$ & $\mathrm{Ar}$ & $H_{\mathrm{E}}$ & $H_{\mathrm{O}}$ & $F_{\mathrm{IS}}$ \\
\hline S04 & 15 & 3 & 0.14 & 0.53 & 0.60 & 1.18 & 0.03 & 0.03 & -0.06 \\
S05 & 64 & 6 & 0.08 & 0.26 & 0.16 & 1.13 & 0.01 & 0.01 & 0.18 \\
S07 & 12 & 2 & 0.09 & 0.48 & 0.84 & 1.09 & 0.04 & 0.06 & -0.47 \\
S08 & 183 & 5 & 0.02 & 0.43 & 0.51 & 1.14 & 0.02 & 0.02 & -0.07 \\
S09 & 16 & 4 & 0.20 & 0.71 & 0.80 & 1.18 & 0.05 & 0.03 & 0.42 \\
S12 & 22 & 2 & 0.05 & 0.41 & 0.75 & 1.09 & 0.02 & 0.02 & -0.13 \\
& 312 & 8 & & & & & & & \\
Overall & 344 & 8 & 0.02 & 0.46 & 0.50 & 1.16 & 0.03 & 0.03 & -0.02 \\
\hline
\end{tabular}

Number number of samples, $G$ number of MLGs detected

$R$ clonal richness index as $R=(G-1) /(N-1)$ (Dorken and Eckert 2001)

$D$ Simpson's index (Arnaud-Haond et al. 2007)

$E$ evenness (Arnaud-Haond et al. 2007)

Ar allele richness adjusted for sample size

$H_{E}$ unbiased expected heterozygosity (Nei 1987)

$H_{o}$ observed heterozygosity

$F_{I S}$ inbreeding coefficient, all

$F_{\text {IS }}$ are not significant departures from $\operatorname{HWE}(P \geq 0.05)$

zero, ranging from 0.01 to 0.05 (Table III). The $F_{\text {Is }}$ ranged from -0.47 to 0.42 ; the HardyWeinberg Equilibrium were not found in all tested populations $(P \geq 0.05)$.

Overall clonal richness was of 0.02 and ranged from 0.02 to 0.20 within apiaries. Overall Simpson's index was 0.46. The lowest Simpson's index was found in S05 $(D=0.26)$ and the highest in S09 $(D=0.71)$. Overall Evenness index was 0.50 and ranged from 0.16 to 0.84 within populations, i.e., MLGs were unequally distributed (Figures 1 and 2). MLGs richness within apiaries (Table III) was not consistently correlated with sample size $(N)$ (Spearman test, $P=0.76)$, for instance, apiary S09 $(N=16)$ had four distinct MLGs and consequently the highest clonal richness $(R=0.20)$ and allelic richness adjusted for sample size $(\mathrm{Ar}=1.18)$.

The genetic differentiation among apiaries, estimated as $F_{\mathrm{ST}}$, ranged from -0.03 to 0.29 , with pairwise $F_{\text {ST }}$ estimates being significant for four pairs of populations (S07 with S04 and S05 with S07, S08, S09, $P<0.05$; Table IV).
Based on the individual Bayesian clustering method implemented in the STRUCTURE software (Supplementary Data, Figure S1), no further recognizable population groups were observed, all the samples both from the High Lands and east coast were considered as a single genetic cluster.

Table IV. Genetic differentiation $\left(F_{\mathrm{ST}}\right)$ between each pair of populations estimated across all loci, (i.e., apiaries with more than 10 individuals successfully genotyped)

\begin{tabular}{lllrll}
\hline Apiary & S04 & S05 & S07 & S08 & S09 \\
\hline S05 & 0.01 & & & & \\
S07 & $0.16^{*}$ & $0.29^{*}$ & & & \\
S08 & 0.02 & $0.02^{*}$ & 0.13 & & \\
S09 & 0.06 & $0.19^{*}$ & -0.03 & 0.07 & \\
S12 & 0.03 & 0.04 & 0.09 & -0.01 & 0.03 \\
\hline
\end{tabular}

Significant pairwise $F_{\mathrm{ST}}$ comparisons at the $P<0.05$ level are indicated with asterisk 


\section{DISCUSSION}

\subsection{Introduction of $V$. destructor in the island}

After the first description of $V$. destructor in Madagascar in 2010, both on the east coast close to the main port of the island and in the area close to the airport (High Lands), the mite has spread to neighboring districts. These two simultaneous mite outbreaks observed $400 \mathrm{~km}$ apart could have either resulted from two independent infestations of $V$. destructor on the island, or from one single event followed by honey bee colony exchanges between the east coast and the capital areas (Rasolofoarivao et al. 2013). Cytochrome oxidase I (COI) gene analysis showed that all mites were of the Korean strain (K1-1) with no genetic variation (Rasolofoarivao et al. 2013). Our nuclear genetic results showed that the same homozygous genotype was overrepresented (almost $69.5 \%$ for MLG 1), and the second most common one (MLG 2) differed by 1 allele only, both were widespread in all apiaries and at the center of the MLG network. Moreover, we found no evidence of admixture from multiple founding populations in the Bayesian cluster analysis, suggesting that $V$. destructor invasion likely result from one major introduction event.

The greater abundance of MLGs in the High Lands (eight MLGs) than on the east coast (only two MLGs) and the presence of particular MLGs in the capital apiaries favor the hypothesis that $V$. destructor has been first introduced in apiary (ies) close to the international airport, and then spread to other regions by commercial exchanges, as most of the goods transit in the capital.

Gene diversity was very low, and the observed heterozygosity was of $3 \%$ within population. Solignac et al. (2005) also found a low heterozygosity of less than $1.3 \%$ (using 13 microsatellites) in 45 populations of mites $(n=565)$ from 17 countries (newly infested countries). Similar results were found by Strapazzon et al. (2009) using four loci in $V$. destructor parasitizing Africanized honeybee subspeciesThe low genetic diversity in $V$. destructor populations affecting A. M. unicolor could be the effect of founding events along the migration to Madagascar and potentially accentuated by anthropomorphic activities (such as mite control, beekeeping practices) in apiaries. As suggested by Solignac et al. (2003), reduced genetic diversity detected in $V$. destructor populations may result from a severe bottleneck, which probably occurred at the time of parasite transfer from A. cerana to A. mellifera (Solignac et al. 2003, 2005). Moreover, the reduced nuclear genetic diversity of $V$. destructor in newly invaded subspecies of $A$. mellifera could be explained by a second strong founder effect (Solignac et al. 2003).

Furthermore, the low level of heterozygosity detected may be explained by autozygosity, which results from recurrent sib-mating (Solignac et al. 2005). The majority of Malagasy beekeepers do not practice transhumance; this factor could limit both ectoparasite spread and multi-infestation of honeybee brood cells by genetically distinct females. A recent study by Dynes et al. (2017) using 10 microsatellite markers on mite populations sampled from apiaries where the first mite infestation occurred more than 30 years ago (in Georgia, USA), showed higher genetic diversity than in other studies made on this parasite. Those results suggest that mite transmission between colonies is maintained by multiple sustained events rather than rare single transmission events. This phenomenon will participate in increasing population diversity, more than previously expected in new invaded areas, implying higher diversity in the future is to be expected in Madagascar, such as its rapid spread and potential apparition of acaricide.

Interestingly, only two MLGs were detected in the population with the lowest $V$. destructor infestation rate, against five and six MLGs detected in the two other apiaries, S08 and S05, respectively. This could be interpreted as genetic diversity arising from high mite fertility and numerous reproductive events. Indeed as underlined by Solignac et al. (2005), heterozygosity in that particular case could be generated by crosses between two lineages in the case of two foundresses entering the same cell.

In conclusion, low levels of genetic diversity were found in $V$. destructor parasiting $A$. $m$. unicolor, which suggest one or multiple introductions of similar genotypes through the airport. 
These data are crucial for the governmental agency to emphasis controls (i) within the country between districts to lower the spread of the mite at the maximum and (ii) at the custom to prevent more introductions from abroad.

\section{ACKNOWLEDGEMENTS}

We would like to thank Niaina Andrianaivoariseta and Dimby Razafindrazaka for their help with data collection. We are grateful to the Malagasy beekeepers who participated in the study. This work is part of the $\mathrm{PhD}$ of Henriette Rasolofoarivao, recipient of a grant of CIRAD-AIRD-Sud. Fieldwork had been partly funded by CIRAD, the Enlargement and sustainability of the Plant Protection Network (ePRPV) project supported by the European Union, the French government, and Réunion collectivities.

\section{AUTHORS' CONTRIBUTIONS}

HD and JC designed protocols; HR did the fieldwork; AS and HR did the lab work; HR, HD, and JC did the analyses; and HR, HD, JC, BR, and LHRR interacted for writing the manuscript.

\section{Diversité génétique de Varroa destructor parasitant Apis mellifera unicolor à Madagascar}

\section{Microsatellite / génotype multi-loci / Acari / Apidae / Madagascar}

Genetische Diversität von Varroamilben (Varroa destructor), die Apis mellifera unicolor in Madagaskar parasitieren

\section{Mikrosatelliten / Multi-Locus-Genotypen / Acari / Madagaskar}

\section{REFERENCES}

Arnaud-Haond S., Belkhir K. (2007) Genclone: A computer program to analyse genotypic data, test for clonality and describe spatial clonal organization. Mol. Ecol. Notes 7, 15-17.

Arnaud-Haond, S., C.M. Duarte, F. Alberto, and E.A. Serrao (2007) Standardizing methods to address clonality in population studies. Molecular ecology 16, 5115-5139.

Barlow N.D., S. Goldson, D. Pimentel (2002) Alien invertebrates in New Zealand. Biological Invasions
Economic and Environmental Costs of Alien Plant, Animal, and Microbe Species. D. Pimentel CRC Press New York, 195-216.

Cornuet, J., M. Beaumont, A. Estoup, and M. Solignac (2006) Inference on microsatellite mutation processes in the invasive mite, Varroa destructor, using reversible jump Markov chain Monte Carlo. Theor. Popul. Biol. 69, 129-144.

De Ruijter A., Pappas N. (1983) Karyotype and sex determination of Varroa jacobsoni Oud. Varroa jacobsoni Oud. affecting honey bees: present status and needs. R. Cavalloro, Commission of the European Communities, Rotterdam, 41-47.

Delatte H., Virgilio M., Simiand C., Risterucci C., De Meyer M., Quilici S. (2010) Isolation and characterization of microsatellite markers from Bactrocera cucurbitae (Coquillett). Mol. Ecol. Res. 10, 576-579.

Denmark, H.A., Cromroy, H.L., Cutts, L. (1991) Varroa mite, Varroa jacobsoni Oudemans: (Acari: Varroidae), Fla. Department Agric. \& Consumer Serv., Division of Plant Industry 347

Dlugosch K., Parker I. (2008) Founding events in species invasions: Genetic variation, adaptive evolution, and the role of multiple introductions. Mol. Ecol. 17, 431449.

Dorken, M.E., and C.G. Eckert (2001) Severely reduced sexual reproduction in northern populations of a clonal plant, Decodonverticillatus (Lythraceae). Journal of Ecology 89, 339-350.

Dynes, T.L., De Roode J.C., Lyons J.I., Berry J.A., Delaplane K.S., Brosi B.J. (2017) Fine scale population genetic structure of Varroa destructor, an ectoparasitic mite of the honey bee (Apis mellifera). Apidologie 48, 93-101.

Evanno G., Regnaut S., Goudet J. (2005) Detecting the number of clusters of individuals using the software structure: A simulation study. Mol. Ecol. 14, 26112620.

Evans J.D. (2000) Microsatellite loci in the honey bee parasitic mite Varroa jacobsoni. Mol. Ecol. 9, 14361438.

Falush D., Stephens M., Pritchard J.K. (2007) Inference of population structure using multi-locus genotype data: Dominant markers and null alleles. Mol. Ecol. Notes 7, 574-578.

Fazier M., Muli E., Conklin T., Schmehl D., Torto B., Frazier J., Tumlinson J., Evans J.D., Raina S. (2010) A scientific note on Varroa destructor found in East Africa; threat or opportunity? Apidologie 41, 463-465.

Franck P., Garnery L., Loiseau A., Oldroyd B.P., Hepburn H.R., Solignac M., Cornuet J.M. (2001) Genetic diversity of the honeybee in Africa: microsatellite and mitochondrial data. Heredity 86, 420-430.

Goudet, J. (2001) Fstat, a program to estimate and test gene diversities and fixation indices (version 2.9. 3)

Handley L., Estoup A., Evans D., Thomas C., Lombaert E., Facon B., Aebi A., Roy H. (2011) Ecological genetics of invasive alien species. Biol. Control 56, 409-428. 
Latreille P (1804) Notice des espèces d'abeilles vivant en grande société, ou abeilles proprement dites et description d'espèces nouvelles. Ann. Mus. Natl. Hist. Nat. 5: 161 à-178.

Leberg P (2002) Estimating allelic richness: Effects of sample size and bottlenecks. Mol. Ecol. 11, 24452449.

Lee CE (2002) Evolutionary genetics of invasive species. Trends Ecol. Evol. 17, 386-391.

Lynch M. (1984) Destabilizing hybridization, generalpurpose genotypes and geographic parthenogenesis. Q. Rev. Biol. 59:257-290.

Martin S., Holland K., Murray M. (1997) Nonreproduction in the honeybee mite Varroa jacobsoni. Exp. Appl. Acarol. 21, 539-549.

Mortensen A.N., Schmehl D.R., Allsopp M., Bustamante T.A., Kimmel C.B., Dykes M.E., Ellis J.D. (2016) Differences in Varroa destructor infestation rates of two indigenous subspecies of Apis mellifera in the Republic of South Africa. Exp. Appl. Acarol. 68, 509-515.

Nei, M. (1987) Molecular evolutionary genetics, Columbia university press. New York.

Pimentel D., Lach L., Zuniga R., Morrison D. (2000) Environmental and economic costs of nonindigenous species in the united states. Biol. Sci. 50, 53-65.

Polzin T., Daneshmand S.V. (2003) On steiner trees and minimum spanning trees in hypergraphs. Operat. Res. Lett. 31, 12-20.

Potts, S.G., Biesmeijer J.C., Kremen C., Neumann P., Schweiger O., Kunin W.E. (2010) Global pollinator declines: trends, impacts and drivers. Trends Ecol. Evol. 25, 345-353.

Pritchard J.K., Stephens M., Donnelly P. (2000) Inference of population structure using multilocus genotype data. Genetics 155, 945-959.

Rasolofarivao H., Clemencet J., Techer M.A. RavelosonRavaomanarivo, L.H., Reynaud B., Delatte H. (2015b) Genetic diversity of the endemic honeybee: Apis mellifera unicolor (Hymenoptera: Apidae) in Madagascar. Apidologie 46, 735-747.

Rasolofoarivao H., Clémencet J., Raveloson-Ravaomanarivo L.H., Razafindrazaka D., Reynaud B., Delatte H. (2013) Spread and strain determination of Varroa destructor (acari: Varroidae) in Madagascar since its first report in 2010. Exp. App. Acarol. 60, 521-530.
Rasolofoarivao H., Delatte H., Raveloson-Ravaomanarivo L.H., Reynaud B., Clemencet J. (2015a) Assessing hygienic behavior of Apis mellifera unicolor (Hymenoptera: Apidae), the endemic honeybee from Madagascar. GMR 14, 5879-5889.

Rousset F. (2008) Genepop'007: A complete reimplementation of the Genepop software for windows and Linux. Mol. Ecol. Res. 8, 103-106.

Ruttner F. (1988) Biogeography and taxonomy of honey bees. Berlin Springer-Verlag

Sakai A.K., Allendorf F.W., Holt J.S., Lodge D.M., Molofsky J., With K.A., Baughman S., Cabin R.J., Cohen J.E., Ellstrand N.C. (2001) The population biology of invasive species. Annu. Rev. Ecol. Syst. 32:305-332.

Solignac M., Vautrin D., Pizzo A., Navajas M., Le Conte Y., Cornuet J.M. (2003) Characterization of microsatellite markers for the apicultural pest Varroa destructor (Acari: Varroidae) and its relatives. Mol. Ecol. Notes 3, 556-559.

Solignac M., Cornuet J.M., Vautrin D., Le Conte Y., Anderson D., Evans J., Cros-Arteil S., Navajas M. (2005) The invasive Korea and Japan types of Varroa destructor, ectoparasitic mites of the western honey bee (Apis mellifera), are two partly isolated clones. Proc. R. Soc. B: Biol. Sci. 272, 411-419.

Strapazzon R., Carneiro F.E., Guerra Jr J.C.V., Moretto G. (2009) Genetic characterization of the mite Varroa destructor (Acari: Varroidae) collected from honey bees Apis mellifera (Hymenoptera, Apidae) in the State of Santa Catarina, Brazil. Gen. Mol. Res. 8, 990-997.

Strauss U., Pirk C.W., Crewe R.M., Human H., Dietemann V. (2015) Impact of Varroa destructor on honeybee (Apis mellifera scutellata) colony development in South Africa. Exp. Appl. Acarol. 65, 89-106.

Strauss U., Dietemann V., Human H., Crewe R.M., Pirk C.W. (2016) Resistance rather than tolerance explains survival of savannah honeybees (Apis mellifera scutellata) to infestation by the parasitic mite Varroa destructor. Parasitology 143, 374-387.

Weir, B.S., and C.C. Cockerham (1984) Estimating F-statistics for the analysis of population structure. Evolution 38, 1358-1370.

Wilcove D.S., Rothstein D., Dubow J., Phillips A., Losos E. (1998) Quantifying threats to imperiled species in the United States. BioScience 48: 607-615. 